\title{
Análise epidemiológica da inquietação populacional acerca de complicações oftalmológicas relacionadas à COVID-19
}

Epidemiological analysis of population concern for ophthalmic complications related to COVID-19

Análisis epidemiológico de la población preocupada por complicaciones oftálmicas relacionadas a

la COVID-19

Tânia Gisela Biberg-Salum ORCID: https://orcid.org/0000-0003-3317-2848 Universidade Estadual de Mato Grosso do Sul, Brasil E-mail: tsalum@uol.com.br

Lara Kristina Silva Lopes

ORCID: https://orcid.org/0000-0002-0554-394X Universidade Anhanguera, Brasil E-mail: 1ksilva18@gmail.com

Maria Eduarda Andreassa Silvestre ORCID: https://orcid.org/0000-0002-7805-9411 Universidade Anhanguera, Brasil

E-mail: dudaandreassa@hotmail.com

Stéphanie de Souza Guedes Carvalho

ORCID: https://orcid.org/0000-0003-4694-2362 Universidade Anhanguera, Brasil E-mail: stephanie.sguedes@gmail.com

Ana Luiza Ceolin Lyrio

ORCID: https://orcid.org/0000-0002-8822-3297 Universidade Estadual de Mato Grosso do Sul, Brasil E-mail: lyrioana@hotmail.com Pedro Henrique Canale

ORCID: https://orcid.org/0000-0001-5426-2389 Universidade Estadual de Mato Grosso do Sul, Brasil E-mail: pedro_canale@ hotmail.com

\begin{abstract}
Resumo
Sabe-se que o coronavírus tem causado, em seu curso patológico, diversas complicações, sendo a síndrome respiratória aguda a principal. Entretanto, ele envolve também outros sistemas e, dentre eles, o oftalmológico. Ao correlacionar-se síndromes virais com infecções oculares, logo se denota o destaque das conjuntivites virais e, em assim sendo, as probabilidades de conjuntivites associadas ao SARS-CoV-2 são consideradas. Portanto, o objetivo deste estudo foi verificar a inquietação populacional quanto ao envolvimento da COVID-19 com complicações oftalmológicas, com um levantamento feito por meio da análise epidemiológica assentada na plataforma Google Trends. Sugere-se, com isso, a importância de ferramentas no contexto da Big Data, para a disseminação de informações, principalmente no período atual da pandemia, por possibilitar pesquisas concernentes às atualidades de indicadores em saúde, ainda que sem realizar coleta de dados em campo. Conclui-se assim que, a partir dos dados apurados na ferramenta utilizada, é sugestivo o interesse da população pelos temas relacionados à COVID-19 e sintomas oftalmológicos, o que pode sinalizar às áreas competentes a necessidade de desenvolvimento de estratégias para divulgação de orientações, bem como o aprofundamento das discussões sobre estes temas.
\end{abstract}

Palavras-chave: Coronavírus; Oftalmopatias; Big data; Conjuntivite; Epidemiologia.

\begin{abstract}
It is known that the coronavirus has caused, in its pathological course, several complications and the main one is the acute respiratory syndrome. However, it also involves other systems and, among them, the ophthalmological. When correlating viral syndromes with ocular infections, the prominence of viral conjunctivitis and, therefore, the probabilities of conjunctivitis associated with SARS-CoV-2 is shown. Then, the aim of this study was to verify the population's concern regarding the involvement of COVID-19 with ophthalmological complications, with a survey carried out through epidemiological analysis based on the Google Trends platform. The study suggests, therefore, the importance of tools in the context of Big Data, for the dissemination of information, especially in the current period of the pandemic, by enabling research concerning the current status of health indicators, even without carrying out data collection in the field. So, the conclusion is, based on the data collected in the tool used, that the population's interest in topics related to
\end{abstract}


COVID-19 and ophthalmological symptoms is expressive, which can signal to the competent areas the need to develop strategies for the dissemination of guidelines, as well as the deepening of discussions on these themes.

Keywords: Coronavirus; Eye diseases; Big data; Conjunctivitis; Epidemiology.

\section{Resumen}

Se sabe que el coronavirus ha provocado, en su curso patológico, varias complicaciones, siendo la principal el síndrome respiratorio agudo. Sin embargo, también involucra a otros sistemas y, entre ellos, al oftalmológico. Al correlacionar los síndromes virales con las infecciones oculares, se muestra la prominencia de la conjuntivitis viral y, por lo tanto, las probabilidades de conjuntivitis asociadas con el SARS-CoV-2 emergen. Así, el objetivo de este estudio fue comprobar la preocupación de la población por la implicación del COVID-19 con complicaciones oftalmológicas, con una encuesta realizada mediante análisis epidemiológico basado en la plataforma Google Trends. El estudio sugiere, así, la importancia de las herramientas en el contexto del Big Data, para la difusión de información, especialmente en el período actual de la pandemia, al posibilitar la investigación sobre el estado actual de los indicadores de salud, incluso sin realizar la recolección de datos en el campo. Por lo tanto, se concluye que, a partir de los datos recolectados en la herramienta utilizada, el interés de la población por temas relacionados con COVID-19 y síntomas oftalmológicos es expresivo, lo que puede señalar a las áreas competentes la necesidad de desarrollar estrategias para la difusión de guías, así como la profundización de los debates sobre estos temas.

Palabras clave: Coronavirus; Oftalmopatías; Macrodatos; Conjuntivitis; Epidemiología.

\section{Introdução}

A epidemiologia constitui-se em tema relevante para pesquisadores e profissionais da saúde, uma vez que estuda o processo saúde-doença e analisa os diferentes fatores que determinam a frequência e a distribuição das doenças na coletividade humana (Gomes, 2015). Ademais, promove a criação de medidas de prevenção, controle ou erradicação de doenças, por meio do fornecimento de indicadores que sejam suporte do planejamento, administração e avaliação das ações em saúde. Tradicionalmente, a epidemiologia convencional está pautada em dados informacionais, os quais são coletados, de forma primária ou secundária em hospitais, clínicas médicas e pesquisas de campo, o que implica, por vezes, em processos onerosos, tanto de custo quanto de tempo (Caldeira, de Souza, de Paula Bedaque \& Papa).

$\mathrm{Na}$ busca constante por informações, hoje em dia vivemos imersos em tecnologias e no mundo digital, experienciando uma revolução nos meios de comunicação que, para além da incontável variedade de dispositivos e ferramentas existentes, ainda agrega um elevado número de usuários. Essa revolução propagou-se, também, ao campo das pesquisas em saúde interferindo, inclusive, no âmbito das coletas de dados de doenças crônicas e infecciosas, pois os dados podem ser obtidas através de uma infinidade de fontes online, incluindo as diferentes redes sociais, blogs, mídias sociais e registros de pesquisas na Web (Salathé et. al., 2012). Esta prática tem sido conhecida como Detecção Digital de Doenças (DDD), cujo uso permite analisar ao conteúdos gerados online pelo grande público, configurando a chamada Epidemiologia Digital (Vayena et al., 2015).

A partir da coleta das informações advindas das mais diferentes fontes, fenômeno que tem crescido vertiginosamente ao longo dos últimos acontecimentos, pelo advento da internet, computadores, softwares e de uma série de ferramentas disponíveis ao nosso meio, as mesmas passam a ser tratadas em bancos de dados, sendo colecionadas no chamado Big Data, que é o termo utilizado para descrever um grande volume de dados, os quais são gerados, guardados, processados e analisados (Rautenberg \& do Carmo, 2019). No campo da saúde brasileira, Chiavegatto (2015) avalia o uso de big data e conclui que a análise deste encontra-se em um ponto de aceleração, a qual tornou-se possível pela confluência de dois fatores, quais sejam, a pressão pela divulgação de resultados de pesquisas públicas e o desenvolvimento computacional necessário para as análises estatísticas. Este mesmo autor entende que o potencial da análise de big data está apenas começando a virar uma realidade na área da saúde e antevê que os epidemiologistas estão em uma posição ideal para liderarem essa nova área.

Atualmente, com as mudanças impostas pela situação pandêmica, torna-se cada vez mais necessário o uso de plataformas digitais para a realização dos mais diferentes tipos de monitoramentos relativos ao comportamento humano (Gonçalves et al., 2020). No campo da saúde, a monitoração das respostas do público online tem sido de grande valia para 
pesquisadores de todo o mundo, a fim de que com isso possam realizar seus estudos, elaborar estratégias de campanhas educativas e analisar o comportamento da população frente a novos danos. A própria população tem se mostrado ávida por pesquisas, principalmente envolvendo o tema da pandemia, a COVID-19, fazendo com que ferramentas de buscas virtuais por informação, registradas em bases de armazenamento, como big data, tornem-se imprescindíveis para a população geral (Bragazzi et al., 2020).

A novação imposta no estilo de vida mundial pela COVID-19, que é uma doença infecciosa causada por um coronavírus (SARS-CoV-2) desconhecido do grande público até o surto em Wuhan, China, ocorrido em dezembro de 2019, passou a despertar, cada vez mais, o interesse de todos quando, a partir de janeiro de 2020, a COVID-19passou a ser considerada, pela Organização Mundial da Saúde (OMS), uma emergência internacional de saúde pública (Garcia Filho, Vieira, \& Silva, 2020). Considerando-se a magnitude da patogenicidade desta doença e as complicações que se manifestam nos mais diferentes sistemas orgânicos, a partir da prática clínica notou-se o envolvimento do aparelho ocular, percepção esta corroborada pela publicação de estudos neste sentido (Biberg-Salum et al., 2021).

Este envolvimento, no contexto do grande público, gerou conflitos e inquietudes e, devido aos desencontros de informações difundidas a respeito do coronavírus, o anseio pelo conhecimento, envolvendo a situação vigente, tornou-se ainda mais evidente e pode ser destacado a partir da busca em ferramentas que dão acesso aos bancos de dados, como é o caso do Google Trends (GT). Esta é uma das inúmeras ferramentas disponibilizadas pela Google Inc., de acesso público e gratuito, que possui uma infinidade de recursos tecnológicos, sendo capaz de refinar pesquisas e analisar, por meio de gráficos, a relevância dada a determinado tema buscado permitindo, inclusive, destacar a localização geográfica das pesquisas realizadas.

Ainda que, para o uso mais eficaz dessa tecnologia de filtragem das informações, sejam considerados uma seleção adequada dos termos de pesquisa, o reconhecimento do alcance ou das limitações dos motores de busca e a capacidade de interpretar a validade do conteúdo disponível em sua tela (Mello et al., 2019), esta ferramenta não representa a opinião de quem faz a busca, pois a mesma sinaliza apenas, uma tendência, uma vez que não é possível saber o motivo de uma dada procura. Ainda assim, esta tem se tornado uma prática crescente no monitoramento de agravos e condições de saúde e de comportamentos relacionados a eles (Garcia Filho et al., 2020).

Portanto, considerando as reflexões expostas, o foco deste estudo foi analisar o interesse do grande público acerca das manifestações oculares oriundas da COVID-19, a partir de uma ferramenta buscadora de dados de big data, com o intuito de verificar a abrangência da epidemiologia digital.

\section{Metodologia}

Trata-se, esta, de uma pesquisa exploratória, transversal, quantitativa e baseada em dados secundários. A coleta de dados se deu em ambiente virtual, no período de março a maio do corrente ano, realizada pelas acadêmicas pesquisadoras. Utilizou como fonte de pesquisa o Google Trends, que é um website da empresa Google, a qual é uma empresa multinacional de serviços online e software dos Estados Unidos, que desenvolve e hospeda diferentes serviços e produtos veiculados pela internet. Já, o Google Trends, é uma ferramenta desenvolvida e utilizada por esta empresa, que se baseia em demonstrar e analisar os termos mais popularmente buscados no Google Search, serviço de pesquisa da mesma empresa nominada, que permite fazer pesquisas na internet sobre qualquer tipo de assunto ou conteúdo. No presente estudo, as palavras chaves utilizadas foram "olhos, conjuntivite, dor e COVID” e suas combinações e o período de levantamento das informações levado em consideração foi aquele estipulado pelo próprio programa do Google Trends, sendo de maio de 2020 a abril de 2021. Com a ferramenta em questão foi permitido refinar as pesquisas e analisar, por meio da apresentação de gráficos gerados por ela própria, o interesse da população pelo referido assunto ao longo dos meses e verificar quais termos foram mais procurados. Ademais, a 
plataforma permitiu, adicionalmente, destacar a localização geográfica, no Brasil, das pesquisas realizadas, permitindo que fosse feito um comparativo entre os resultados fornecidos pelo Google Trends e pesquisas apresentadas em boletins epidemiológicos dos estados onde a doença é mais prevalente, acerca dos temas pesquisados pelas palavras-chaves. Dessa forma, os Resultados serão apresentados e discutidos levando em consideração as oportunidades de análises apresentadas pela própria ferramenta de pesquisa. Quanto aos aspectos éticos direcionados às pesquisas, levando-se em conta as definições dos protocolos ora vigentes, ao entender-se que o presente estudo nelas não se enquadrava, prescindiu-se de envio do mesmo para apreciação em Comitê de Ética em Pesquisas com Seres Humanos.

\section{Resultados}

Com os resultados deste estudo é possível vislumbrar, a partir dos dados a seguir apresentados, o impacto dos meios de comunicação, o quanto os mesmos têm colaborado com a população, de maneira geral, na elucidação de dúvidas, esclarecimento de temores e curiosidades, inclusive ao se atentar-se em dados epidemiológicos, não somente como meros números mas, também, a identificar a abrangência destes na própria saúde, destacando o envolvimento da Epidemiologia Digital.

A plataforma "Google Trends", cuja tradução de trends é tendências, apresenta seus resultados em forma de gráficos, aqui explicitados pelas Figuras abaixo ilustradas. Esses gráficos expressam a variação do número de buscas de um termo ou assunto, ao longo do tempo, indicando o interesse do público quanto a esse tema.

Em linhas gerais, o gráfico é composto por um eixo vertical que expressa o volume das buscas e um eixo horizontal, que representa a temporalidade. Dessa forma, os níveis mais altos do gráfico representam picos de popularidade, os mais baixos indicam diminuição da popularidade e, finalmente, um valor de 0 significa que não havia dados suficientes sobre o termo, pois dados pouco pesquisados, informações pessoais e buscas repetidas pelo mesmo indivíduo em curto espaço de tempo são excluídas. Além disso, a própria plataforma traz em seus gráficos o intervalo de tempo transcorrido para a procura pelos termos. Uma vez que foram utilizados termos de busca no idioma português, os resultados abaixo apresentados enfocam as regiões brasileiras.

Figura 1 - Buscas pelo termo "covid e olhos".

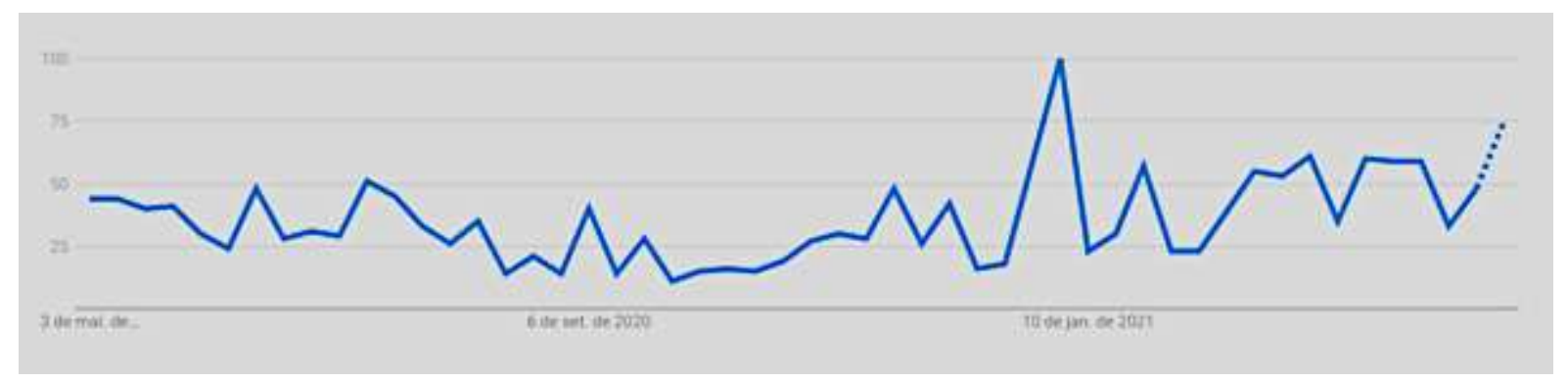

Fonte: Google Trends.

O termo de busca "covid e olhos" teve seu pico de popularidade nas busca no mês de janeiro de 2021 (Figura 1) e, ao lançar-se um olhar para as regiões brasileiras, aquela que mais demonstrou interesse por essa palavra-chave foi o Nordeste, sendo Sergipe o estado que ocupa o primeiro lugar (Figura 2). Na tentativa de se comparar esse dado com boletins epidemiológicos, não foi possível mensurar a situação epidemiológica em cada estado por meio das informações disponibilizadas pelo DATASUS (Departamento de Informática do SUS), porventura em função desta patologia ser ainda bastante incipiente por ocasião do presente estudo, sendo que os dados não apareciam nas bases do SINAN (Sistema de Notificação de Agravos de Notificação) como Doença e Agravo de Notificação. (Brasil, 2021). 
Figura 2 - Estados que mais registraram buscas pelo termo "covid e olhos".

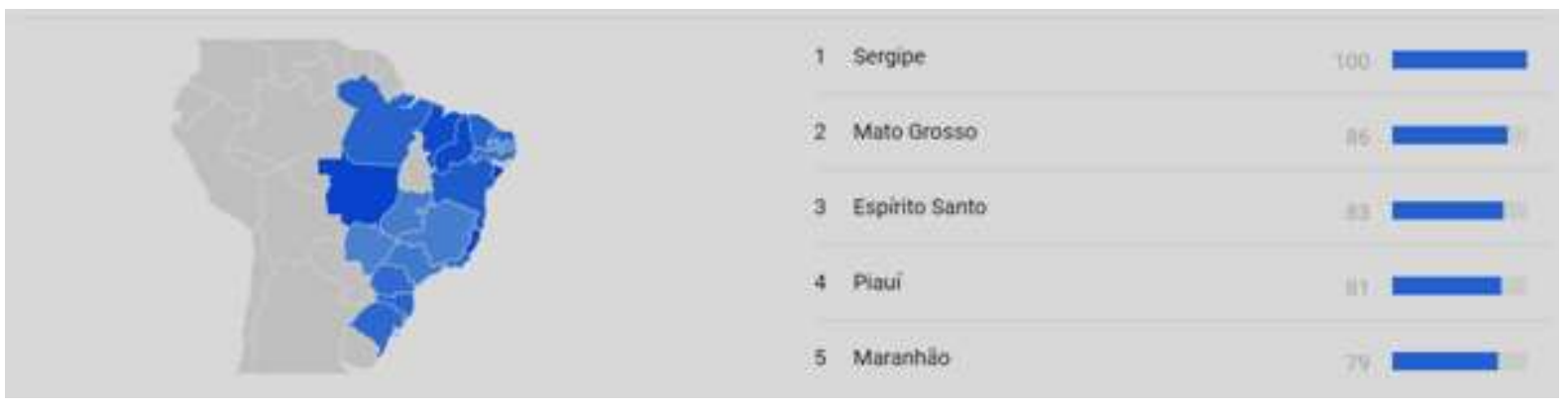

Fonte: Google Trends.

Para outra combinação de palavras utilizadas como fonte de busca na internet, "conjuntivite e covid", os resultados estão ilustrados na Figura 3. Justifica-se esta seleção de termo tendo em vista que a conjuntivite pode ser precipitada por uma infecção viral, inclusive pela COVID-19, como demonstram alguns estudos (Biberg-Salum et al., 2021; Chen et al.,).

Figura 3 - Buscas pelo termo "conjuntivite e covid"

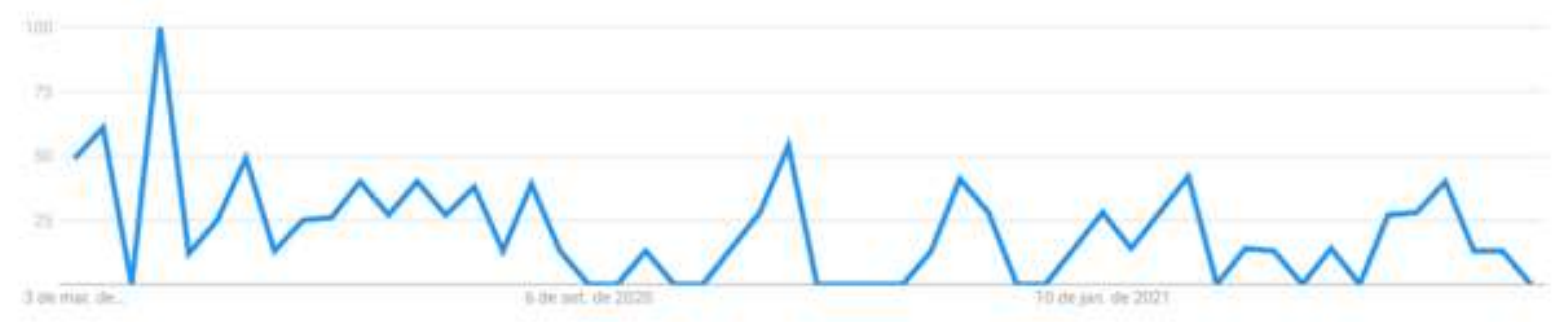

Fonte: Google Trends.

Para esta combinação de termos percebe-se a manifestação de vários picos de popularidade ao longo dos meses, os quais se entremeiam com descensos chegando a zero, inclusive, demonstrando uma irregularidade do interesse do público. Os estados onde se registrou maior interesse por esse tema estão na região Sudeste, como demonstrado na figura (Figura 4) abaixo.

Figura 4 - Estados que mais registraram buscas pelo termo " conjuntivite e covid".

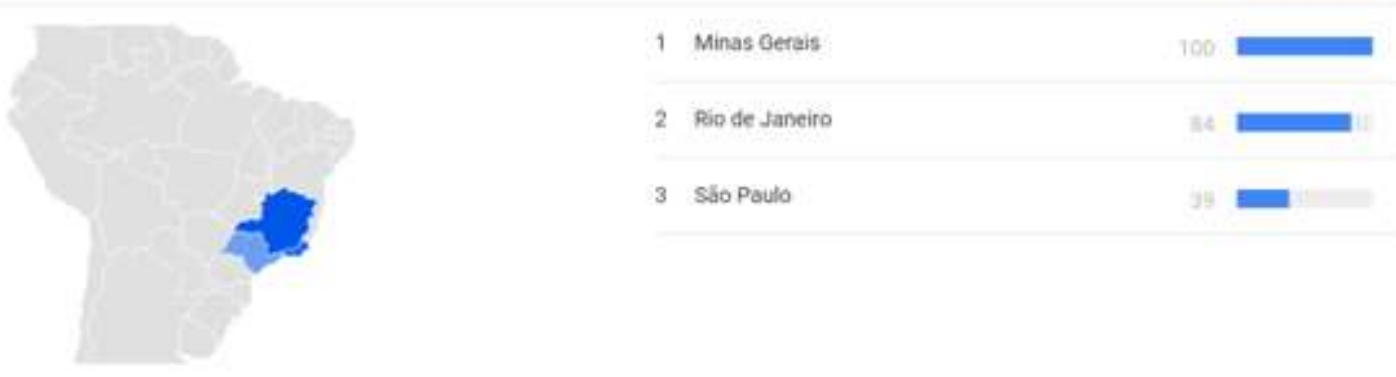

Fonte: Google Trends.

A Figura 5 apresenta uma curva comparativa entre os termos "conjuntivite" e "conjuntivite e covid", destacando a temporalidade o interesse ao longo dos meses. Percebe-se que a média de buscas pelo termo "conjuntivite" esteve sempre mais elevada do que pela combinação "conjuntivite e covid", ainda que o pico de ambas tenha se manifestado no mesmo período. 
Figura 5 - Comparativo de termos buscados ao longo do tempo-conjuntivite.

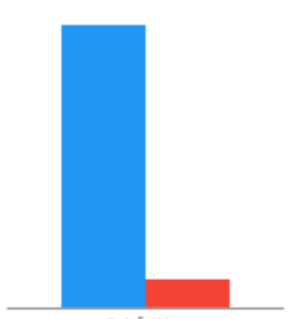

Média

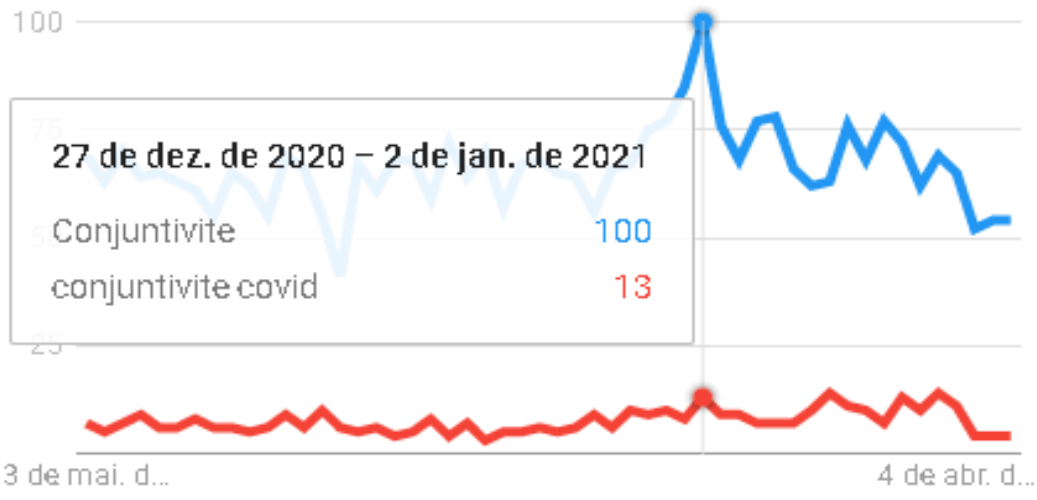

Fonte: Google Trends.

Outro termo pesquisado no Brasil, ao longo dos 12 meses estudados, foi "dor atrás dos olhos e covid”, sendo que curva de popularidade apresenta-se ilustrado na Figura 6. Não foi possível avaliar o interesse por regiões do Brasil, em função da insuficiência de dados apresentados pelo sistema.

Figura 6 - Buscas pelo termo "dor atrás dos olhos e covid" ao longo do tempo. Interesse ao longo do tempo

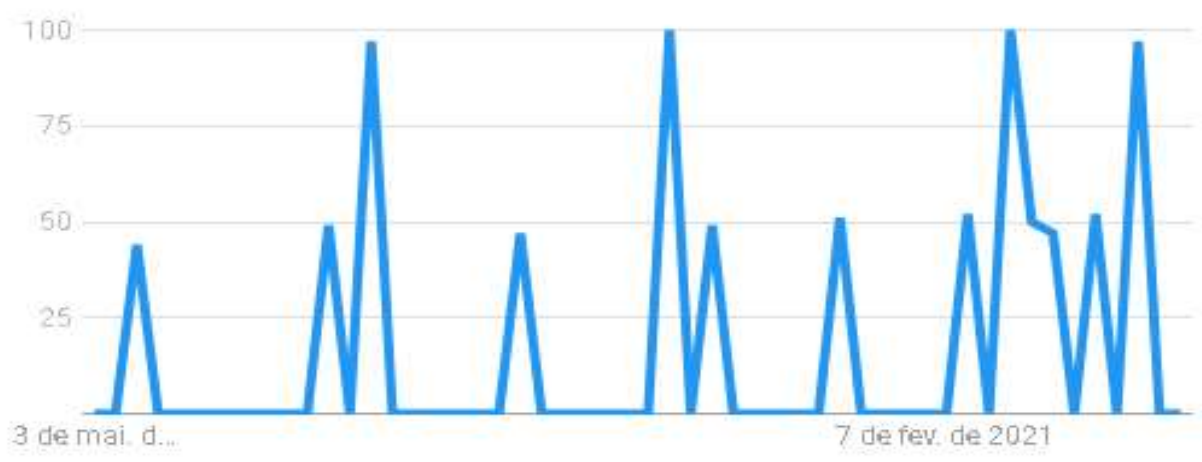

Brasil. Últimos 12 meses. Pesquisa Google na Web.

Fonte: Google Trends.

Apesar da estreita semelhança aparente entre o termo de busca da Figura 7, "dor atrás dos olhos covid", e o termo anterior, da Figura 6, as curvas demonstraram um traçado de popularidade diferente para o mesmo período temporal, sugerindo, quiçá, que o recrutamento das informações tende a ser variado a depender de variações tênues dos termos de busca. 
Figura 7 - Buscas pelo termo "dor atrás dos olhos covid" ao longo do tempo.

$$
\text { Interesse ao longo do tempo }
$$

\section{Dor atrás dos olhos covid}

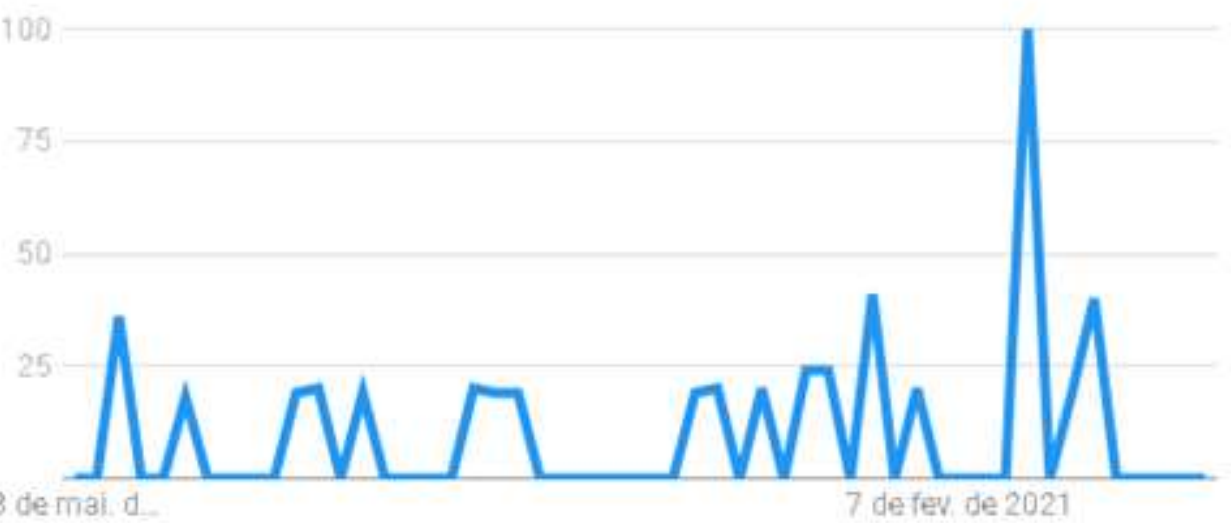

Brasil. Últimos 12 meses. Pesquisa Google na Web.

Fonte: Google Trends.

Quanto à distribuição dos picos de interesse, por sub-regiões, para este termo "dor atrás dos olhos covid", o estado do Rio de Janeiro foi o que registrou mais buscas, conforme demonstrado na Figura 8.

Figura 8 - Estados que mais registraram buscas pelo termo "dor atrás dos olhos covid".

Interesse por sub-regiăo 8

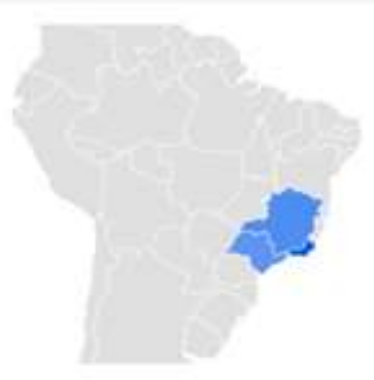

Subregiás * \pm\langle\rangle$<$
1 Plo de Janeiro
2 Minas Gerais
3 Să Paulo

Fonte: Google Trends

De acordo com a Figura 9, ao serem comparadas as buscas pelos temas "dor atrás dos olhos covid" e "dor atrás dos olhos" é possível inferir que há uma maior associação para a causa de dor atrás dos olhos buscada ser por COVID-19, visto que há uma coincidência no pico de popularidade de ambas as pesquisas. 
Figura 9 - Comparativo de termos buscados ao longo do tempo-dor atrás dos olhos.

Interesse a longa do tempo

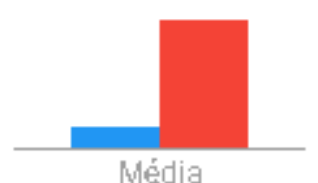

Média
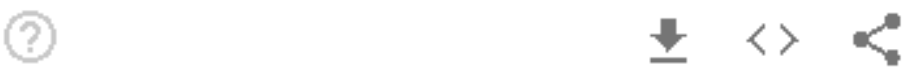

28 de fev. -6 de mar. de 2021

dor atrás dos olhos covid

dor atrás dos olhos

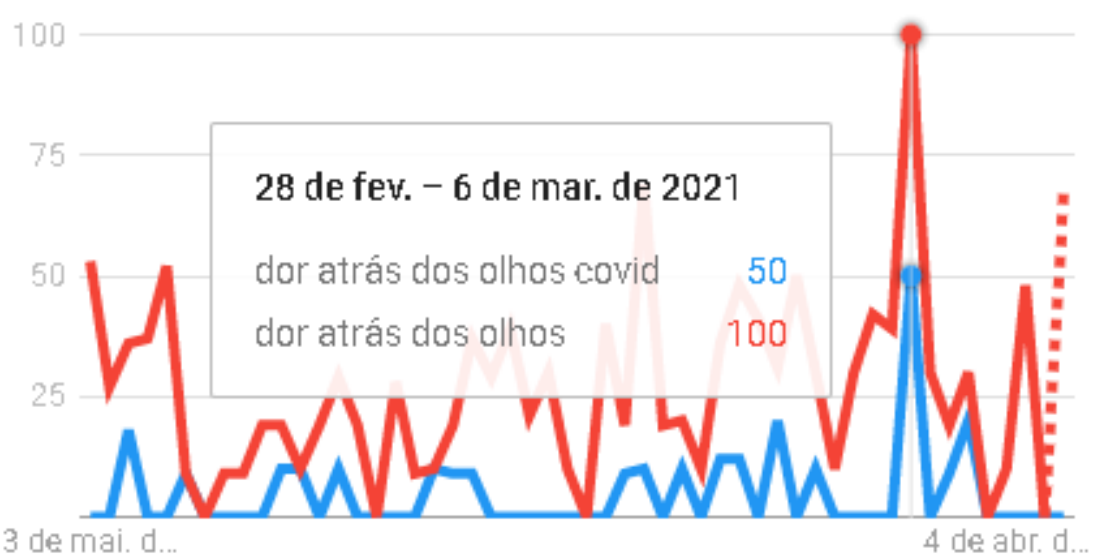

Fonte: Google Trends

Também foi manifestado interesse pelo termo "dor ocular covid" nas buscas realizadas, podendo os picos de interesse ser observados na Figura 10.

Figura 10 - Buscas pelo termo "dor ocular covid" ao longo do tempo.

Interesse ao longo do tempo

Google Trends

Dor ocular eovid

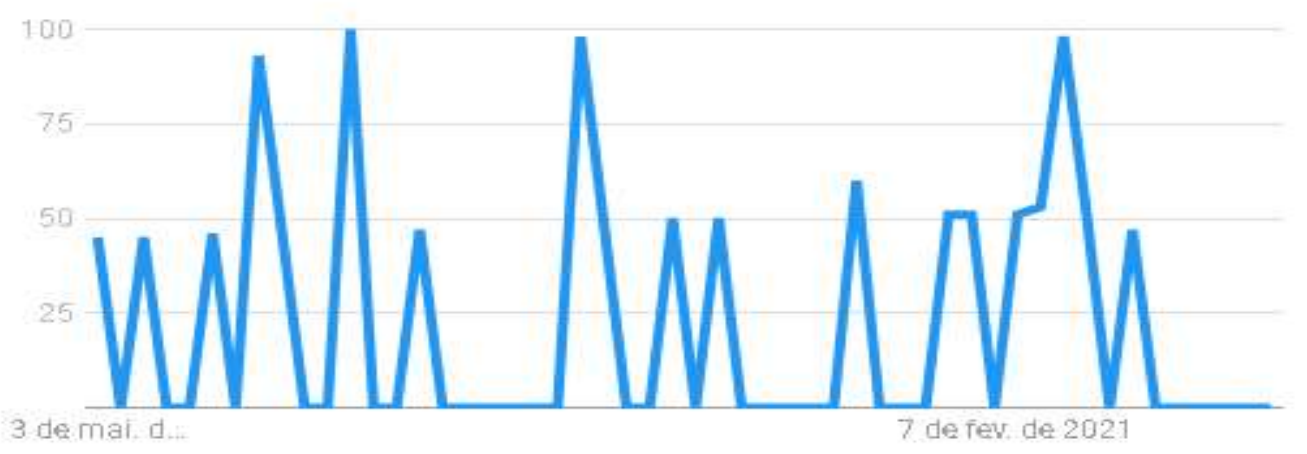

Brasil. Ûltimos 12 meses. Pesquisa Google na Web.

Fonte: Google Trends. 
Na comparação dos termos "dor ocular covid" e "dor ocular" foi constatado que o pico de popularidade deste último" ocorreu no momento em que "dor ocular covid" apresentou número 0 de interesse de pesquisa no Brasil, conforme demonstrado na Figura 11.

Figura 11 - Comparativo de termos buscados ao longo do tempo-dor ocular.
Interesse ao longo do tempo
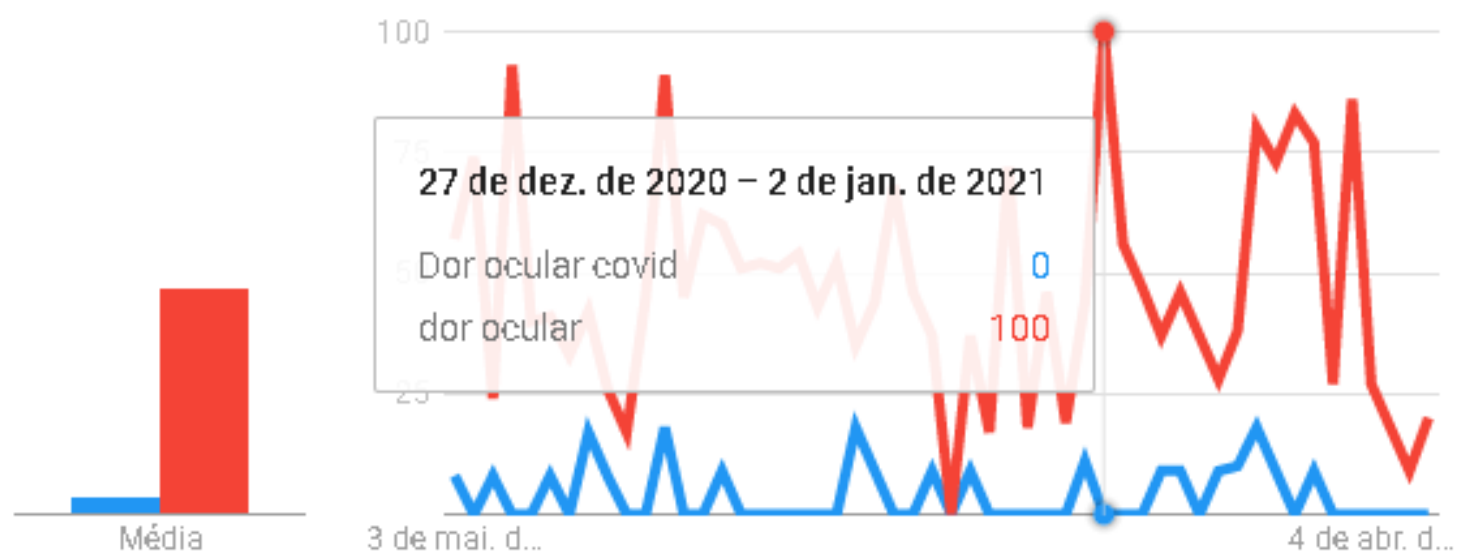

Fonte: Google Trends.

Com estes resultados oriundos de uma ferramenta buscadora de dados na internet aliada a outra que promove o armazenamento e processamento destes, é possível sugerir que, vistas as comparações realizadas entre os termos selecionados, a população demonstrou interesse nas buscas referentes à associação entre sintomas oculares e COVID-19. Outrossim, não foi possível verificar se houve associação entre os níveis de interesse nas buscas pelos determinados termos e os índices demonstrados para oftalmopatias e COVID-19oriundos das informações geradas pelo SINAN, uma vez que os dados neste se apresentaram insuficientes para a correlação intencionada.

\section{Discussão}

A epidemiologia é a ciência que estuda o processo saúde-doença em coletividades humanas. Ela analisa a distribuição e os fatores determinantes das enfermidades, danos à saúde e eventos associados à saúde coletiva (Rouquayrol \& Gurgel, 2021). Portanto, por meio desses estudos ela propõe medidas de prevenção, controle e tratamento de agravos e doenças. Ademais, com base no estudo de determinado agravo/doença e consequente desfecho, a epidemiologia também propõe indicadores que auxiliam como suporte para o planejamento e avaliação das medidas de saúde que podem ser tomadas (Universidade Federal de Santa Catarina, 2016).

Em épocas de surtos, epidemias e pandemias, o conceito de epidemiologia acaba sendo difundindo de forma mais ampla para a população, tendo em vista o próprio interesse da mesma para com esse assunto. Atualmente, com a pandemia do novo coronavírus, o interesse e a preocupação com a saúde promoveram o fomento das pesquisas na área da saúde, tendo em vista que essa doença precisa ser descrita de forma sustentada para os novos manuais e protocolos de saúde. Tendo isso em vista há, ainda, 
muito a se debater sobre o assunto e, para tanto, existem diversos sites e plataformas que colaboram para o sucesso das pesquisas epidemiológicas.

O Google Trends é uma dessas plataformas de pesquisa disponibilizada pública e gratuitamente pela Google Inc., a qual possui o recurso de, por meio de palavras-chave, verificar a evolução da pesquisa por determinado assunto em determinado período (Arora et al., 2019). Dessa forma, ela verifica não só a evolução, mas também a quantidade de buscas, os assuntos mais recorrentes no período selecionado e as pesquisas relacionadas ao tema proposto pela palavra-chave que o pesquisador selecionar. Dessa forma, esse recurso do Google Trends, surgiu como uma alternativa para o desenvolvimento de pesquisas epidemiológicas que poderiam ser realizadas, anteriormente, em campo, como a coleta de dados, por exemplo. Além disso, a plataforma fornece gráficos de evolução de pesquisa e, também, permite que o pesquisador faça comparações sobre determinado tema, com mais de uma palavra-chave selecionada, propiciando assim maior enriquecimento para a pesquisa com maior acurácia dos dados.

A doença COVID-19 apresenta como sintomas, principalmente aqueles relacionados ao acometimento das vias aéreas, todavia, também há relatos de comprometimento extrapulmonar (Loon et al., 2004). Apesar de não ser o quadro clínico clássico da doença, a infecção pelo vírus SARS-CoV-2 demonstrou cursar com complicações oftalmológicas, sendo a mais comum entre elas, a conjuntivite (Torres et al., 2020; Scalinci, \& Trovato Battagliola, 2020). Em virtude disso, ao longo da pandemia, ficou demonstrado o aumento no interesse pelos termos selecionados neste estudo, relacionando "olhos, conjuntivite, dor atrás dos olhos, dor ocular e covid".

Quanto aos resultados do presente estudo, percebe-se certa limitação, uma vez que o foco do mesmo esteve restrito à a uma única ferramenta de pesquisa e esta não detalha o perfil do público que realizou a pesquisa com os termos descritos acima, logo, não foi possível elaborar um padrão de acometimento ocular em infecções pelo vírus SARS-CoV-2. Ademais, o presente trabalho também é limitado pelo fato de que a plataforma apresenta apenas o número de buscas pelos termos, o que torna improvável determinar as causas que levaram às buscas. Todavia, como pontos fortes, a ferramenta utilizada no estudo possui a qualidade de apresentar, em tempo real, os mais populares termos buscados em várias regiões do mundo e em vários idiomas, ainda que este não tenha sido o caso deste trabalho. Além disso, as evidências de que a superfície ocular seja um local de infecção pelo coronavírus-2 e que há necessidade de uso de óculos ou proteção facial para reduzir o risco de infecção ocular por coronavírus (Willcox et al., 2020) estimula a população a aumentar a preocupação e curiosidade em casos de sinais e sintomas oculares durante a pandemia.

\section{Conclusão}

Conclui-se, com base no exposto, que as atuais ferramentas de pesquisa em base de dados, como a utilizada na presente pesquisa (Google Trends) são de suma importância para o embasamento de novas pesquisas no contexto atual de pandemia e outras e que, em assim sendo, considera-se que o presente estudo contribuiu beneficamente para demonstrar à população e, principalmente para as autoridades responsáveis por vigilância e epidemiologia de saúde, que há necessidade de atentar-se às mais variadas oportunidades de obtenção de informações e coleta de dados, no sentido de fomentar as medidas de prevenção e controle de quaisquer patologias ou agravos à saúde, tanto para os profissionais da saúde, como também para o grande público.

Ainda assim, considera-se a necessidade de estudos futuros que contemplem, de forma mais ampliada, aspectos aqui percebidos como limitantes para uma compreensão mais robusta desta temática, quais sejam a comparação entre o desempenho ou as características de duas ou mais plataformas de armazenamento de dados, ou ainda, a análise dos achados frente ao perfil populacional participante destas buscas. 
Desta forma exalta-se, em cumprimento aos objetivos deste estudo, a importância destas ferramentas que auxiliam na disseminação do conhecimento para a população em geral, bem como aquelas que se aproximam das propostas da Epidemiologia Digital.

\section{Referências}

Arora, V. S., McKee, M., \& Stuckler, D. (2019). Google Trends: Opportunities and limitations in health and health policy research. Health Policy, 123(3), 338341.

Bragazzi, N, L., Dai, H., Damiani, G., Behzadifar, M., Martini, M., \& Wu, J. (2020). Como o big data e a inteligência artificial podem ajudar a gerenciar melhor a pandemia COVID-19. Jornal internacional de pesquisa ambiental e saúde pública ,17 (9), 3176.

Biberg-Salum, T. G., Lyrio, A. L. C., \& Canale, P. H. (2021). Ocular manifestations of COVID-19: A narrative literature review. Research, Society and Development, 10(6), e51310615979. https://doi.org/10.33448/rsd-v10i6.15979.

Brasil. Ministério da Saude (MS). Sinan - Sistema de Informação de Agravos de Notificação. Portal da Saúde. O que é o Sinan. [homepage on the internet]. http://dtr2004.saude.gov.br/sinanweb/index.php?name=Tnet.

Caldeira, A. L. G., de Souza, D. L. B., de Paula Bedaque, H., \& Papa, T. D. Estudos Epidemiológicos-Conceitos Gerais. Descomplicando, 15.

Chen, L., Liu, M., Zhang, Z., Qiao, K., Huang, T., Chen, M., Xin, N., Huang, Z., Liu, L., Zhang, G., \& Wang, J. (2020). Ocular manifestations of a hospitalized patient with confirmed 2019 novel coronavirus disease. The British journal of ophthalmology, 104(6), 748-751. https://doi.org/10.1136/bjophthalmol-2020316304

Chiavegatto, A. D. P. (2015). Uso de big data em saúde no Brasil: perspectivas para um futuro próximo. Epidemiologia e Serviços de Saúde, 24, 325-332. https://doi.org/10.5123/S1679-49742015000200015. https://doi.org/10.5123/S1679-49742015000200015.

Garcia Filho, C., et al. (2020). Buscas na internet sobre medidas de enfrentamento à COVID-19 no Brasil: descrição de pesquisas realizadas nos primeiros 100 dias de 2020. Epidemiologia e Serviços de Saúde, 29(3), e2020191. https://dx.doi.org/10.5123/s1679-49742020000300011

Gomes, E. C. (2015). Conceitos e ferramentas da epidemiologia. Ed. Universitária da UFPE.

Gonçalves, P. B., Coutinho, D. R., \& Kira, B. (2020). Vírus e Telas: o direito econômico das plataformas digitais na pandemia de COVID-19. Revista Direito e Práxis.

Loon, S. C., Teoh, S. C., Oon, L. L., Se-Thoe, S. Y., Ling, A. E., Leo, Y. S., \& Leong, H. N. (2004). The severe acute respiratory syndrome coronavirus in tears. The British journal of ophthalmology, 88(7), 861-863. https://doi.org/10.1136/bjo.2003.035931

Mello, A., Caetano, J., \& Souza, C. (2019). Como aprender Googlando: O Google Trends e suas possibilidades metodológicas para o letramento digital em pesquisa.. Anais do Encontro Virtual de Documentação em Software Livre e Congresso Internacional de Linguagem e Tecnologia Online, 7(1). http://www.periodicos.letras.ufmg.br/index.php/anais_linguagem_tecnologia/article/view/15082

Rautenberg, S., \& do Carmo, P. R. V. (2019). Big data e ciência de dados: complementariedade conceitual no processo de tomada de decisão. Brazilian Journal of Information Science: research trends, 13(1), 56-67.

Rouquayrol, M. Z., \& Gurgel, M. (2021). Rouquayrol: epidemiologia e saúde. Medbook.

Salathé, M., Bengtsson, L., Bodnar T. J., Brewer, D., D., Brownstein, J. S., Buckee, C., Campbell, E. M., Cattuto, C., Khandelwal, S., Mabry, P. L., Vespignani, A. (2012). Digital epidemiology. PLoS Comput Biol 8(7):e1002616. 10.1371/journal.pcbi.1002616

Scalinci, S. Z., \& Trovato Battagliola, E. (2020). Conjunctivitis can be the only presenting sign and symptom of COVID-19. IDCases, 20, e00774. https://doi.org/10.1016/j.idcr.2020.e00774

Torres, B. R. S., Cunha, C. E. X., Castro, L. R., Brito, L. M. P., Ferreira, C. V. O., \& Ribeiro, M. V. M. R. (2020). Ocular manifestations of COVID-19: a literature review. Revista da Associação Médica Brasileira.

Universidade Federal de Santa Catarina. (2016). Especialização Multiprofissional na Atenção Básica - Modalidade a Distância. Universidade Federal de Santa Catarina.

Vayena, E., Salathé, M., Madoff, L. C., \& Brownstein, J. S. Ethical challenges of big data in public health. PLoS Comput Biol. 2015 Feb 9;11(2):e1003904. 10.1371/journal.pcbi.1003904.

Willcox, M. D., Walsh, K., Nichols, J. J., Morgan, P. B., \& Jones, L. W. (2020). A superfície ocular, coronavírus e COVID-19 Clinical and Experimental Optometry.;103:418-24 